\title{
Endophyte survival during seed storage
}

NICHOLAS HILL

Agrinostics Ltd. Co., Watkinsville, GA

Commercial seed lots of Flecha/AR542, Jesup/AR542, Jesup/ $\mathrm{AR} 584$, and Grasslands Advance/AR542 were stored at $25^{\circ} \mathrm{C}$ for 18 months. Seeds were planted into seedling trays every month and grown for 42 days under greenhouse conditions. Seedlings were tested for endophyte presence to estimate viable endophyte in seed. Endophyte survival was greatest in Flecha/AR542 (84\%) and least in AdvanceAR542 (0\%) after 18 months. Endophyte survival was greater in Jesup/AR584 (24\%) than Jesup/AR542 $(10 \%)$. These data suggest that Mediterranean endophyte/host associations are more adapted for endophyte survival in seed. 